\title{
ON THE ANALYSIS OF OLD FLOURS.
}

\section{By M. M. Baliand and V. Planchon.*}

Oud flour, which has reached the extreme limit of its possible preservation, and has therefore lost its commercial value, has lately been employed in a new traffic which constitutes an actual fraud. By re-passing such an article through the mill with fresh flour, the mixture escapes detection by trade experts, and passes current as genuine new flour. The apparent goodness, when fresh from the mill, rapidly passes off, however, and, in a very short time, the whole becomes stale. M. Balland has recently had occasion to examine several samples of such flour, with the following results: the proportions both of water and ash were normal; while that of the fat was much less, and the acidity much greater, than the usual amount. The first sample, although really the most ancient, had only issued from the mill within three months, while samples Nos. 2 and 3 were also of the same nature, although not quite so bad.

\begin{tabular}{|c|c|c|c|c|c|c|}
\hline & & & $\begin{array}{c}\text { Water } \\
\text { per cent. }\end{array}$ & $\begin{array}{c}\text { Ash } \\
\text { per cent. }\end{array}$ & $\begin{array}{c}\text { Acidity } \\
\text { per cent. }\end{array}$ & $\begin{array}{l}\text { Fat. } \\
\text { per cent }\end{array}$ \\
\hline Sample No. 1 & & .. & $13 \cdot 70$ & $1 \cdot 10$ & $0 \cdot 147$ & $0 \cdot 78$ \\
\hline$, \quad, 2$ & .. & . & $13 \cdot 82$ & 032 & 0.069 & 0.94 \\
\hline " $\quad 3$ & .. &. & $13 \cdot 92$ & $0 \cdot 34$ & 0.074 & 0.84 \\
\hline New Flour A & .. & . & $13 \cdot 16$ & 0.36 & 0.039 & $1 \cdot 22$ \\
\hline , $\quad$ B & .. & .. & $13 \cdot 20$ & $0 \cdot 76$ & 0.049 & $1 \cdot 74$ \\
\hline$\Rightarrow \mathrm{C}$ & .. & . & $13 \cdot 96$ & $0 \cdot 38$ & 0.049 & $0 \cdot 76$ \\
\hline
\end{tabular}

The estimation of the gluten gives excellent indications, being less cohesive than the gluten of fresh flours,

If it be extracted in the usual manner, and then left under water for twentyfour hours, and if, at the expiration of that time, the washing and squeezing between the fingers be resumed, it froths and loses much of its weight. The following table will show the difference in this respect between genuine young flours and the mixtures now under consideration:-

\begin{tabular}{|c|c|c|c|}
\hline 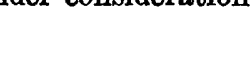 & & $\begin{array}{l}\text { Original gluten } \\
\text { per cent. }\end{array}$ & $\begin{array}{l}\text { Gluten, after twenty-four } \\
\text { hours in water, per cent. }\end{array}$ \\
\hline Sample No. 1 .. & . & $29 \cdot 6$ & $18 \cdot 0$ \\
\hline$", \quad, 2 \ldots$ & $\ldots$ & $36 \cdot 4$ & $27 \cdot 2$ \\
\hline ",,$\quad 3 \ldots$ & $\ldots$ & $36 \cdot 0$ & $26 \cdot 4$ \\
\hline New Flour A .. & .. & $38 \cdot 8$ & $34 \cdot 8$ \\
\hline,$\quad$ B .. & $\ldots$ & $36 \cdot 0$ & $32 \cdot 4$ \\
\hline$\Rightarrow \quad, \quad$ C .. & $\cdots$ & $36 \cdot 0$ & $31 \cdot 2$ \\
\hline
\end{tabular}

It is therefore evident that the amounts of acidity and of fat and the behaviour of the gluten permits us to pronounce upon the age of the flour, and also enables us to differentiate between a stale and a good flour even when the former is comparatively freshly made.

M. Planchon has made the following experiments :--After quoting the researches of M. Balland to the effect that the normal acidity of good flour represented in monohydrated sulphuric acid can vary between .015 and $\cdot 040$ per cent., he says "One can well conceive that the precise estimation of such small quantities of acid presents consider- 
able difficulties, especially when we consider that the titration is performed in an alcoholic liquor, resulting from the prolonged maceration of several grams only of flour, and with turmeric paper as an indicator. It is true that in following exactly the method of operation described, I have always obtained, when working with good flours, figures comprised within the indicated limits; nevertheless, I believe that these figures, although comparable amongst themselves, do not represent the real acidity, because $I$ have obtained very different results by operating in the following manner:-

"Five grams of flour are gradually mixed with 50 c.c. of cold distilled water; when the mixture is perfectly homogeneous two or three drops of alcoholic solution of phenolphtlein are added, and the whole is titrated with $\frac{1}{20}$ normal soda solution, such solution being delivered from a delicate burette, and the whole being kept in constant agitation during the titration. The number of c.c. of soda used is multiplied by the coefficient $\cdot 0245$, and the figure so obtained gives, in my opinion, the actual acidity of the flour.

To obtain the exact point of neutrality it is necessary to compare the colour with that of a mixture of five grams. of the same flour with 50 c.c. of water, and the same number of drops of the indicator. The operation is so short that the action of the water and the ferments do not cause the formation of any notable quantity of acid. I. have proved that when a mixture of flour and water is allowed to stand the amount of the total acidity does not increase during the first two hours. Here, for example, is the result of the titration of the same flour maintained in contact with water for different periods :-

$$
\begin{aligned}
& \text { Total Acidity per Cent. } \\
& \left(\mathrm{H}_{2} \mathrm{SO}_{4}\right) \text {. }
\end{aligned}
$$

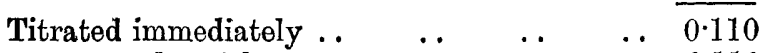

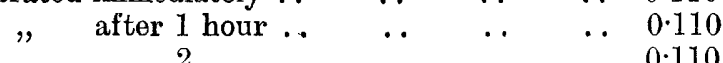

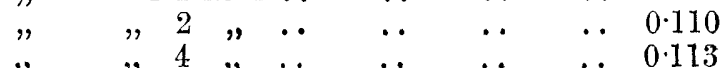

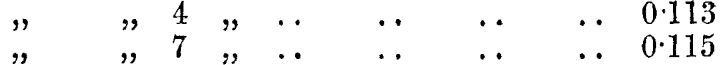

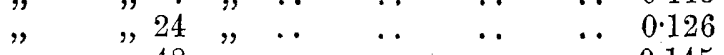

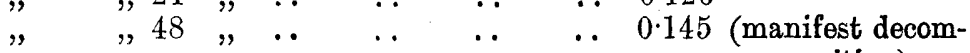

If the total acidity remains the same for two hours, it is still much larger than the amount of acid that enters into solution, because in measuring the acidity of the liquid separated by filtration from the same mixtures I obtained the following results :-

Soluble Acidity per Cent.

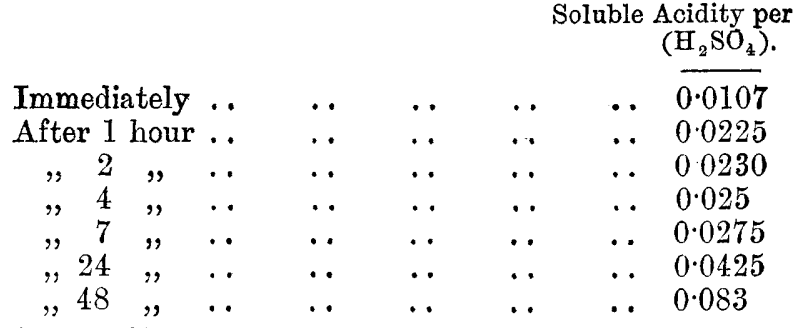

Maceration in rectified spirit of the same flour during twenty-four hours showed after filtration the presence of 03 per cent. of acidity soluble therein. We thus see that flour does not give up its total acidity immediately either to water or alcohol, 
and that the only true method is to directly apply the alkali to the flour itself, in presence of water. I have tested this method of analysis on eleven samples of fresh flour, and from nine of them which were cylinder ground I have obtained a total acidity varying between $\cdot 105$ and $\cdot 122$. The remaining two flours, which were from ordinary stone mills, showed respectively $\cdot 119$ and $\cdot 133$ per cent. of total acidity. I have also had occasion to analyse two samples of flour manifestly damaged and unfit for use in the bakery. In the one case I obtained 16 and in the other 565 of total acidity. In both of these cases the estimation of the total acidity furnished exceedingly characteristic results, and I consider this simple operation ought never to be neglected in the examination of flour intended for bread-making.

On the Estimation of Nitric Acid by Conversion into Ammonia, and Observation of the Deficit of Hydrogen. By K. Ulsch (Zeitsch. $f$. Anal. Chem. Vol. 30, p. 175).-The use of zinc for the reduction of nitric acid brings about a loss of nitrogen, owing to the production of nitrous acid. If, however, metallic iron is taken for the reduction, no nitrites are produced. When the reaction is carried out at a temperature of about $70^{\circ} \mathrm{C}$. it is completed in less than half an hour. The author operates as follows:-A small flask, provided with a triple-bored rubber cork, through one hole of which passes a tapped funnel tube, through the second and third two glass tubes bent at right angles, one reaching to the bottom of the flask, is connected with a nitrometer. Into the flask are placed 3 grammes of iron powder (ferrum redactum), and 20 c.c. of a copper solution containing 100 grammes $\mathrm{CuSO}_{4}$ per litre. The contents of the flask are heated gently, until the Huid is no longer blue. The precipitate is then washed with several quantities of warm water. The flask is now closed and connected with the nitrometer; 10 c.c. of normal sulphuric acid are then added through the funnel tube and the flask warmed in the water-bath to $75^{\circ} \mathrm{C}$. until there is no more evolution of hydrogen. The apparatus is now free from air. Once more 10 c.c. of standard acid are added, and the hydrogen produced is measured after it has cooled down to the ordinary temperature, corrections being of course applied for temperature and pressure. The flask is then emptied by means of the tube going to the bottom of the flask, and the nitrate solution to be examined introduced with 10 c.c. of normal acid. The deficit of hydrogen obtained gives the measure of the quantity of nitrate present. 1.106 c.c. hydrogen corresponds to one milligramme of potassium nitrate. The test experiments given are in every way satisfactory. A single charge of 3 grammes. of iron suffices for 25 determinations, if the amount of nitrate does not exceed 10 milligrammes in each case.

O. $\mathrm{H}$.

A New Method for the Quantitative Separation of Manganese and Zinc. P. Jannasch and J. F. Madgregory (Jour.f. prakt Chem. [2] 43, 402-406).-Manganese can be completely precipitated as dioxide in an ammoniacal solution by hydrogen dioxide. To ensure the freedom of the precipitate from zinc, when that metal is present, excess of ammonium chloride and ammonia must be employed. The authors experimented with $0.5 \mathrm{grm}$. of re-crystallised manganese and zinc sulphates respectively, dissolved in 75-100 c.c. of water, following the method here set forth :-The solution is acidified 
with hydrochloric acid, and transferred to a 600 c.c. Berlin porcelain dish; there are then added successively at least 100 c.c. of a $15-20$ per cent. solution of ammonium chloride, $60-100$ c.c. of strong ammonia, and an excess (50-60 c.c.) of hydrogen dioxide, the dish being covered with a clock glass to avoid loss by the spurting which occurs from escape of oxygen when the hydrogen dioxide is in excess. The dish is then heated for 10-15 minutes on the water-bath, the precipitate collected on a filter and washed, first with hot ammonia water, and finally with hot pure water, until the washings leave no residue or evaporation. The precipitate can be burnt in a platinum or porcelain crucible while still wet, and must finally be heated over the blowpipe until constant in weight.

To determine the zinc, the mixed filtrate and washings may be precipitated with ammonium sulphide, the zinc sulphide being re-dissolved and precipitated as carbonate in the usual way. A more rapid method, however, is to evaporate the filtrate and washings, dry the residue at $125-150^{\circ}$ for one hour, and ignite it over a piece of asbestos mill-board to expel ammonium salts; the asbestos is to prevent the temperature from rising high enough to volatilize zinc salts, its presence renders it necessary to push the salts down from the sides of the dish into the centre. The ignited residue is dissolved in water containing a little hydrochloric acid, and the zinc precipitated from the hot solution with sodium carbonate in the usual manner.

A. G. B.

The Esthmation of Fat in Milk by means of the Lactocrite. L. F. Wilson, Chem. Zeit., 1891, 15, 649-656).-The growing importance of dairy products and their production as a definite industrial undertaking, requiring the aid of some means of readily checking the quality of the raw material, milk, both to ascertain its commercial value and to determine in what degree the yield from cows and other milk-giving animals can be improved by breeding, have led to the device of numerous methods for the estimation of the constituent with which the butter-maker is most concerned, viz., the fat. The most expeditious method hitherto proposed is that of De Laval, who in applying the principle of the separators in use on a large scale, to the analytical problem stated above, has given us an instrument, the lactocrite, which appears to attain the desired end more perfectly than any other known means.

The construction and mode of use of the lactocrite are well known to our readers (for a description see the ANALYst, 1887, 130). Its accuracy and ease of working have been testified to by many chemists, and it is now made so that it can be driven by hand instead of power. The chief objection that can be urged against the lactocrite, is that it fails to indicate the presence of any fat whatever in skim milk containing less than about 0.5 per cent. of fat, and that its readings up to 1.5 per cent. require the application of a considerable and varying correction ( $f f$. Faber, The Analyst, 1887, 130). The cause for this seems to lie not in the construction of the apparatus itself, but in the fact that the mixture of sulphuric acid and glacial acetic acid, which is used to dissolve the casein and allow the separation of the fat, attacks the latter to some extent. By substituting for this a mixture of hydrochloric acid and lactic acid in proportions similar to those of the acids they replace, this difficulty is entirely overcome. The modified process has been patented by the Separator Company of Stockholm. The chemist to this com- 
pany, M. Ekenberg, has devised a process for preparing lactic acid, by which it will be so much cheapened that the cost of using the lactocrite under the new conditions will be scarcely greater that it was formerly (for another new process for the preparation of lactic acid see Journal of the Society of Chemical Industry, 1891, 312).

The author has compared the indications of the instrument used with the altered acid mixture, with the results given by various analytical processes of repute. A brief description of each method as carried out by him is first given.

\section{Laval's Lactocrite Method.}

The instrument used was supplied by the Separator Co., and was of the size known as "baby," having places for twelve tubes and driven by hand. The milk and acid were measured by the same pipette, it being, of course, previously rinsed with the liquid about to be measured. In testing whole milk the mixture was kept in the water-bath for eight to ten minutes, while for skim milk six to eight minutes sufficed. The lactocrite was heated to $50.60^{\circ} \mathrm{C}$., by means of steam, and the rotation continued for about five minutes at the usual speed of 6,000-7,000 revolutions per minute. Each sample was tested either six or twelve times, the results boing usually identically or, in any case, very closely concordant for the same sample. In a few instances a bubble made its appearance in the column of fat in the capillary portion of the lactocrite tube, in which case the experiment was rejected. If an apparatus of somewhat larger size, e.g., one with twenty-four tubes be used and the operator have assistance in washing up, etc., some two dozen tests per hour can be made, so that with two persons familiar with the instrument, and working alternately, 300-400 tests can be carried out in an ordinary working day. It is thus remarkable not only as the first analytical apparatus dependent upon mechanical power, but also results are obtained by it more speedily than by any known analytical process whatever.

\section{Soxhlet's Areometric Method.}

(Zeit. Landwirth. Ver. Bay. München, 1880).

The apparatus used by the author was obtained from J. Greiner, of Munich, and was accompanied by two cortificates by the inventor stating that the two hydrometers sent therewith were accurate. When tested against ordinary gravimetric methods for the analysis of whole milk the process was found perfectly satisfactory.

The ethereal fat solution was always brought, in the test experiments, to the normal temperature of $17.5^{\circ} \mathrm{C}$., by means of a stream of water of that temperature supplied from a vessel holding about 15 litres kept continuously running through the water-jacket, and thus all correction for temperature was avoided. The ether was purified before use by treatment with calcium chloride and caustic lime, distilled and saturated with water at the ordinary temperature.

No difficulty in separating the ethereal from the aqueous layer was experienced either with whole or skim milks, a circumstance that may have been due to the fact that the samples were fresh.

\section{Gravimetric Methods.}

Of the methods that depend on the absorption of the milk by some porcus substance, such as sand, pumice-stone, asbestos, cotton, wool, and the like, and the extraction of the fat from the total solids thus finely divided, the author has used the following :- 
(a) Pumice-stone, broken and sifted, so as to produce a material of which the particles were $0.5 .1 .0 \mathrm{~m} . \mathrm{m}$. in diameter, is washed with water, ignited, and about twelve grms. placed in a porcelain basin. About 12 grms. of milk are then allowed to drop upon it so as to be thoroughly absorbed, dried at $97-98^{\circ}$ C., the operation being completed in a vacuous water oven, kept exhausted by a water-pump. The residue is transferred to a paper cartridge and extracted with ether in a Soxhlet apparatus in the ordinary way, any particles adhering to the dish being removed by a little more pumice and a plug of pure cotton-wool. The paper cartridge is made of best Swedish filterpaper used double, which has been extracted for at least twelve hours with ether, and thoroughly dried, and is supported on a layer of cotton-wool similarly purified, to retain any fine particles of pumice that may find their way through.

The ether used in extraction is freed from water and alcohol by the method described under (2), supplemented by treatment with sodium until hydrogen ceases to escape, and final distillation.

Good as pumice-stone is, its pores are too large for perfect division of the particles of milk solids, the fat globules remaining encased in casein to some extent, a fact evidenced by the perceptible extra yield of fat obtained by pulverising the pumice, and re-extraction after previous thorough exhaustion.

(b) In pursuance of the principle of J. Lohmann's method, which consists in the use of clay plates as an absorbent, the author has employed powdered, lightly burnt clay vessels, freed from dust by washing with water on a sieve, so as to leave particles about 0.5 to $1.5 \mathrm{~mm}$. in diameter. The process is carried out in the same way as with pumice-stone, save that 22 grms. of the absorbent material are taken instead of 12.

The extraction apparatus used by the author consisted of a battery of four Soxhlet tubes, with flasks and condensers ground in, thus avoiding the use of corks. Each flask was supported by a small porcelain dish containing a little sand, heated by means of a jet of gas from the small inner gas tube of a bunsen burner, the flame being so placed that one side of the basin was heated and bumping thus avoided. By this arrangement the rate of extraction could be easily regulated, and the syphon of the Soxhlet discharged about every five minutes. In order to prevent the formation of bubbles in the ether collected in the extraction tube, a paper shield was placed round the extractor just above the flask. As the flow of ether out of the double paper cartridge, and through the underlying plug of cotton-wool, is somewhat slow, a little piece of cotton-wool is inserted into the mouth of the syphon, so that the rate at which the extraction tube is emptied is also decreased. The use of a sand-bath instead of a water-bath for the extractor flasks is advantageous, as their weights remain practically constant and they last much better.

Test analyses were made of whole and skim-milk, to ascertain how long the extraction should be continued in order to be complete. It was found that three hours generally sufficed for the extraction of fat from whole milk, but that twelve hours were necessary for skim milk containing about 0.8 per cent. of fat.

(c) The author also examined Adams' process, and quotes the opinicns of Klein, Richmond, and others as to its accuracy, mentioning that it tends to yield higher results than the other methods. In his investigations be used Schleicher and Schüll's "fat- 
free paper," having first ascertained what quantity of matter soluble in ether was present in it. The amount found was just over $1 \mathrm{~m}$.grm. for each strip, that being the form in which the paper is sold. Extraction of the paper with ether for two hours removes this impurity.

Experiments made to determine the length of time for which extraction had to be continued to dissolve the fat from the milk solids showed that three hours were ample, thus confirming Adams' statement. Nevertheless, the author adopted the period of five hours for whole milk, and twelve hours for skim milk, to avoid possibility of error. He records the fact that of all the methods tried, the Adams' process showed the closest concordances in successive experiments.

The following table shows the mean results of the different methods with various samples of milk :-

\begin{tabular}{|c|c|c|c|c|}
\hline $\begin{array}{c}\text { Powdered } \\
\text { earthenware. }\end{array}$ & Lactocrite. & Areometer. & $\begin{array}{l}\text { Blotting } \\
\text { paper. }\end{array}$ & Remarks. \\
\hline $3 \cdot 66$ & $3 \cdot 71$ & $3 \cdot 71$ & $3 \cdot 74$ & Morning milk from cow No. 7 . \\
\hline $3 \cdot 63$ & $3 \cdot 62$ & $3 \cdot 68$ & 373 & Morning milk from cow No. 3 . \\
\hline $3 \cdot 09$ & $3 \cdot 13$ & $3 \cdot 18$ & $3 \cdot 18$ & \\
\hline $3 \cdot 08$ & $3 \cdot 10$ & - & - & Morning milk from several cows. \\
\hline $2 \cdot 67$ & $2 \cdot 72$ & $2 \cdot 77$ & $2 \cdot 76$ & \\
\hline $2 \cdot 55$ & $2 \cdot 52$ & $2 \cdot 56$ & 2.60 & Morning milk from cow No. 13. \\
\hline $2 \cdot 38$ & $2 \cdot 43$ & $2 \cdot 49$ & $2 \cdot 49$ & $\begin{array}{l}\text { Morning milk from cow No. } 14 \text {. } \\
\text { Mixture of two parts of hand-skimmed }\end{array}$ \\
\hline $2 \cdot 19$ & $2 \cdot 23$ & $2 \cdot 34$ & $2 \cdot 28$ & $\left\{\begin{array}{l}\text { milk, } 24 \text { hours old, with one part of } \\
\text { morning milk from cow No. } 14 .\end{array}\right.$ \\
\hline $1 \cdot 35$ & $1 \cdot 41$ & $1 \cdot 47$ & $1 \cdot 43$ & Milk, 24 hours old, from several cows. \\
\hline $0 \cdot 85$ & $0 \cdot 90$ & $1 \cdot 02$ & 0.94 & Milk, 48 hours old, from several cows. \\
\hline $0 \cdot 76$ & $0 \cdot 82$ & $0 \cdot 94$ & $0 \cdot 86$ & \\
\hline - & 0.69 & - & 0.74 & Milk "separated" by hand "separator." \\
\hline - & $0 \cdot 42$ & - & $0 \cdot 48$ & \\
\hline $0 \cdot 31$ & - & $0 \cdot 50$ & $0 \cdot 40$ & Milk " separated" by \\
\hline- & $0 \cdot 28$ & - & $0 \cdot 33$ & driven by power. \\
\hline
\end{tabular}

The differences between the three methods that give the best and most concordant results, viz., the Adams process, the powdered earthenware method, and the lactocrite, are as follows :--

$\begin{array}{lllccc} & & & \text { Maximum. } & \text { Minimum. } & \text { Mean. } \\ \text { Between Adams and earthenware } & \ldots & \ldots & +0.11 & +0.05 & +0.088 \\ \text { Between Adams and lactocrite } & \ldots & \ldots & +0.11 & +0.02 & +0.052 \\ \text { Between lactocrite and earthenware } & \ldots & +0.06 & -0.03 & +0.035\end{array}$

It therefore appears that the lactocrite used with the new solvent mentioned at the beginning of this paper gives thoroughly reliable results with the most diverse kinds of milk.

Soxhlet's areometric method is less accurate than the lactocrite, particularly with skim milks. The reason for the constant tendency of the Adams process to give higher results than any method in which an absorbent other than blotting-paper is used, appears to be due to the interstices of the blotting-paper being so fine that the fat globules fail 
to penetrate into them, and remain, therefore, on the surface already largely freed from the milk serum, and consequently are easily dissolved by the ether.

The porous earthenware method gives lower results, because the sample used by the author was not safficiently close in texture, but this disadvantage he considers in some measure counterbalanced by the facts that no special care is needed to free it previously from matter soluble in ether, and that it can be used repeatedly after mere ignition, the presence of the ash from the milk increasing its powers as an absorbent.

The author supplements the foregoing work with a description of some experiments made by him on the use of kaolin as an absorbent as proposed by Dr. Norblad.

Kaolin is elutriated, and the finest portions cast into plates in plaster of Paris moulds, burnt at a sintering temperature, broken up and washed on a sieve until uniform particles about $0.5-1.5 \mathrm{~mm}$. in diameter are obtained. The material thus prepared and used in the proportion of 25 grammes to 10 grammes of milk gave results closely approximating to those obtained by the Adams process, and is in every way equal to it save in the greater care needed to transfer it to the extractor.

The conclusions arrived at in this exhaustive and important paper are as follows:-

1. The lactocrite used with a mixture of hydrochloric and lactic acids gives results quite comparable with those obtained by the best gravimetric processes.

2. Kaolin prepared and used as described, and when dry extracted directly with ether, gives figures agreeing with those arrived at by the Adams process.

3. The Adams process leaves nothing to be desired if the strips of paper be first thoroughly extracted with ether.

4. The aerometric method, though giving very small errors for milks containing more than 2.5 per cent. of fat, is unreliable for poor and skim milks, and is altogether of more limited applicability than the foregoing processes.

B. B.

Analysis of Butter and Other Fats. By J. König and F. Hart. (Zeits $f$. Anal. Chem., Vol. 30, p. 292.) - The authors add one more to the numerous modifications of older methods. Following the proposal of J. West-Knights (ANALYsT, Vol. 5), they convert the fatty acids into the baryta salts, and estimate the amount of combined baryta. They operate as follows:-About five grammes of the fat are placed in a graduated 300 c.c. flask, 50 c.c. of alcohol are added, heated on the water-bath until all fat is dissolved ; 40 c.c. hot baryta solution, containing 17.5 barium hydrate in 100 c.c., are then added, and the mixture boiled under a reflux condenser, with addition of a few pieces of pumice, for three to four hours. The solution is then allowed to cool, water is added to the mark, and filtered. Through 200 c.c. of the filtrate carbonic acid is passed until the reaction is no longer alkaline, the whole is then boiled in a porcelain basin nearly to dryness, allow to cool, make up to 250 c.c., and 200 c.c. filtered off; to the clear filtrate dilute sulphuric acid is added (the original says hydrochloric acid and barium chloride), and the $\mathrm{BaSO}_{4}$ weighed. The quantity found is multiplied by 0.657 to obtain the amount of caustic baryta, combined with the soluble fatty acids, this is then multiplied by $\frac{3}{2}$. The authors call the figure so obtained the baryta value of the soluble fatty acids. They also make a blank experiment, by the 
results of which the original figure is corrected. The following baryta values have been obtained :-

Linzeed $18 \cdot 7$, poppy $7 \cdot 0$, olive $9 \cdot 4$, colza $17 \cdot 6$, sesame $6 \cdot 9$, earthnut $22 \cdot 9$, cotton $29 \cdot 1$, liver oils from $25 \cdot 2$ to $52 \cdot 8$, palm-kernel oil $86 \cdot 3$, coco-nut oil $118 \cdot 5$, coco-butter $195 \cdot 1$, six samples of butter-fat $238 \cdot 5,216.9,221 \cdot 5,216 \cdot 4,236 \cdot 0,199 \cdot 6$; beef-fat $35 \cdot 8$, mutton fat $4 \cdot 9$, lard $17 \cdot 1$, three samples of margarine $21 \cdot 6,21 \cdot 7,22 \cdot 8$.

The baryta value of fats therefore runs, in general, parallel with the ReichertWollny figure. In the six samples of butter just quoted the Wollny figure was $30 \cdot 7$, $29 \cdot 0,28 \cdot 7,28 \cdot 2,27 \cdot 5,26 \cdot 3$. The variations of the baryta values are, therefore, much wider than those of the volatile fatty acids. It is difficult, therefore, to understand the reasoning by which the authors come to the conclusion that their method surpasses the Reichert. Wollny, as regards simplicity, and equals it as to sharpness of distinction.

\section{O. H.}

Volumetric Estimation of Manganese. By L. Blum (Zeits. $f$. Anal. Chem. Vol. 30, p. 284).-This is a modification of Donath and Hattensaur's method (Chem. Zeit. 1890, p. 323). It depends upon the fact that in a manganese solution, which contains tartaric acid, ammonium chloride, and a ferric salt, and rendered ammoniacal, potassium ferrocyanide precipitates the whole of the manganese as mangan-ammonium-ferrocyanide. The iron is not precipitated under these conditions. A standard solution is made of 10 grammes cryst. $\mathrm{MnCl}_{2} 4 \mathrm{H}_{2} \mathrm{O}$ in 500 c.c. water ; $50 \mathrm{c}$ c. of this are pipetted into a beaker, a few drops of ferric chloride, 20 c.c. of cold saturated ammonium chloride and 30 c.c. tartaric acid solution and ammonia are added, the fluid heated to boiling, and titrated with a ferrocyanide solution containing 38.487 grammes. pure crystallised potassium ferrocyanide per litre, each c c. of this being equal to 005 gramme manganese. The end-reaction is obtained by taking out from time to time a drop of the solution and bringing it together upon a white plate with a drop of dilute acetic acid, which, when the ferrocyanide is in excess, produces the blue colour of prussian blue.

The author compares his method with Volhard's permanganate method, with which it agrees very well. He adds the warning, not to rely implicitly upon the purity of the ferrocyanide, as this salt sometimes contains much sodium in place of potassium.

$$
\text { O. } \mathrm{H} \text {. }
$$

Detection of Sesame Oil in Olive Orl. J. T. Tocher, A.1.C. (Pharm. Journ., Jan. 24, 1891).-Prepare a solution of pyrogallol in pure hydrochloric acid. Measure $\frac{1}{2}$ oz. of this solution into a wide-mouthed test tube provided with a cork, and add $\frac{1}{2} \mathrm{oz}$. ( $1 \mathrm{oz}^{\cdot}$ if the adulteration be small) of the oil to be tested. Shake well, and allow the oil and acid to separate. Draw off supernatant liquid with pipette, and boil the hydrochloric acid solution for about five minutes, when, if sesame oil be present, the colour of the solution will have changed to purple. The purple develops slowly on boiling. The colour by transmitted light is wine-red to purple, and, by reflected light, blue. Of oils of known composition treated in this way, pure olive gave a faint yellow; sesame, deep purple; 20 per cent. sesame, purple; 5 per cent. sesame, faint purple; 1 per cent. sesame, very faint purple ; almond, colourless ; ground nut, colourless ; cotton-seed, very faint red ; sun flower, faint olive ; rape, colourless, 